\title{
Reflections on a Decade of Using the Scholarship of Teaching and Learning
}

\author{
Randall E. Osborne, PhD \\ Professor, Department of Psychology \\ Texas State University at San Marcos \\ Paul Kriese, PhD \\ Associate Professor, College of Humanities and Social Sciences \\ Indiana University East \\ Heather Tobey \\ Student, Department of Psychology \\ Texas State University at San Marcos \\ This article explores lessons learned from a decade of teaching an online course on \\ the politics and psychology of hatred using a scholarship of teaching and learning \\ (SoTL) model. The authors illuminate course etiquette and a critical thinking model \\ that incorporates SoTL into the ongoing fabric of the classroom. In addition, \\ discussion centers on utilizing SoTL to satisfy colleagues concerned about "loss of \\ content" in process oriented courses, and how to engage students in an ongoing, \\ ever-changing, dialogue that can lead them to accept a more inclusive world view.
}

\section{Introduction}

Hutchings and Shulman (1999) utilize the following definition for the scholarship of teaching:

A scholarship of teaching is not synonymous with excellent teaching. It requires a kind of "going meta," in which faculty frame and systematically investigate questions related to student learning-the conditions under which it occurs, what it looks like, how to deepen it, and so forth-and do so with an eye not only to improving their own classroom but to advancing practice beyond it (p. 13).

As we worked to develop an Internetbased course on the politics and psychology of hatred, we discovered that the same critical questioning and inquiry process that defines the SoTL process for the teacher can be used as a means by which students could examine their own learning and faculty can assess student work. In other words, we believed that the same process of: (1) posing a question, and (2) systematically examining that question through evidence, could become the manner by which students learn, NOT just the process by which

As we worked to develop an Internet-based course on the politics and psychology of hatred, we discovered that the same critical questioning and inquiry process that defines the SoTL process for the teacher can be used as a means by which students could examine their own learning and faculty can assess student work.

we, as faculty, examine what and how they learn. By using what we have learned about SoTL, we were able to set cognitive and affective expectations for the course and to assist students in developing the skills to make progress in implementing the SoTL process. As we begin the next decade of teaching this course, we reflect on lessons learned from these ten years of applying the method and outline how we "train" students to use it.

Our foray into the SoTL arena was both fortuitous and accidental. One author had been building a career in teaching and research centered on issues of institutional racism in the form of government and governmental doctrine (in particular the U.S. Constitution). Another author incorporated an interest in the development, maintenance, and implications of prejudicial attitudes into his 
teaching and research in the discipline of psychology. At the root of our work was a fundamental belief that most people could learn to be more inclusive in their worldview. Inclusiveness, for both of us, was defined by the work of Thomas and Butler (2000) as "the practice of emphasizing our uniqueness in promoting the reality that each voice, when valued, respected, and expected to, will provide a positive contribution to the community." The discovery of this root goal in our work led us to one complex question, "how can we develop a purposeful methodology for teaching the critical questioning and evidence examining skills that are necessary to create 'inclusive citizens'?"

As we grappled with this question, we kept returning to a relatively new (at that time) concept in pedagogy, "scholarship of teaching and learning." That was the accidental beginning of our foray into SoTL. It turned out to be fortuitous, however, as neither of us had tenure and had no idea that the course we were about to develop would rankle some of our senior colleagues. As we briefly discuss the decade of work that has now passed under the rubric of SoTL in our course, we will address the following issues:

1) how SoTL assisted us in satisfying our skeptical senior colleagues as to the "integrity" of our process driven course;

2) how SoTL has provided us a framework for addressing the issue of content within a course that changes with each new group of students and each new series of local, state, national, and international events;

3) how we, as faculty, can change with the times as a result of SoTL;

4) how we incorporate SoTL into the affective and cognitive expectations for students in the course;

5) reflections (and some student feedback) as to the degree to which an Internet-based course assists or hinders our goal of utilizing a SoTL procedure in our course; and

6) reflections (and some student feedback) as to the degree to which our different disciplinary backgrounds foster or inhibit a SoTL process in this team-taught course.

\section{History}

When we first proposed an interdisciplinary Internet course on the politics and psychology of hatred, we were surprised by the negative reaction of some of our senior colleagues. Questions such as, "how can you assess student learning?", "what exactly will students be learning?", and "maybe you should wait until you get tenure to try something like that" were, unfortunately, commonplace. Fortunately, we discovered SoTL as a pedagogy that provided a framework for us to discuss the goals of the course. By focusing on the desired outcomes of SoTL, we were able to satisfy our colleagues that, at a minimum, no harm would be done to students. Once we were committed to using a SoTL model in our course, we began to search for ways to describe that model and the learning outcomes we anticipated because of using it.

By exploring the question and evidence gathering techniques employed by our colleagues in a variety of disciplines (e.g., Streveler, Moskal \& Miller, 2003; Wagner, 2005; Walker, 2002), we were able to synthesize what we believed to be a model for SoTL that we would (1) employ in our course, (2) nurture students to employ, and (3) hold students accountable for employing via assignment and course grades. The model and course etiquette we feel is necessary to foster growth and use of the SoTL model in our course is outlined in a later section. For the new faculty member considering integrating SoTL into courses, we highly recommend such a model as a framework for tenure and promotion conversations about one's teaching philosophy and for documenting teaching effectiveness. For a moment, however, let us turn our attention to a recurring question colleagues asked us when we described our desire to create this interdisciplinary exploration of values (e.g., Hall 2003; Morrison, 2001) in our course. 


\section{Content vs. Process}

The content of the course is actually determined by process. It is determined by student issues, by issues in the world at the time of the course and over its duration. There are general outlines for the course, but these are starting points for discussion. This past semester, issues such as the Jenna, LA event, and the Columbia University racist episode guided our discussion about how hatred is exampled and who is involved. We always have scenarios and exercises about environmental and situational racism and hatred. But events only provide the 'content' for this course. Over the ten years we have taught this course, events have provided us with examples which we then incorporate into the course 'process' and go from there. When we look at our variation of the nuclear fallout shelter (who will die?) exercise, for example, the exercise remains the same, but students assigned to different groups and/or from different semesters make different judgments which affect the direction of the course. As situations occur, then, those events can immediately be placed into the ongoing dialogue of the course and be used to encourage discussion and link content to student lives. The event may take a week or the rest of the semester to discuss and digest.

\section{How We Demonstrate the "Process" of SoTL}

Everyone in the class and all events in the world become potential exercises for the class. Since the faculty are always looking for examples to illustrate the course, content-rich situations consistently occur to us. We are process-oriented. Class constantly changes shape and direction. We believe that personal experience is essential 'material' to demonstrate the flow of human behavior exampled in this class. Personal experience of one person often links with personal experience of another. These crosspollinating events show students that life is a fascinating mélange of human patterns. We are the 'course'; our personal experiences are the 'stuff' of the course. As we interrelate our lives with each other, the course takes on different realities but still has a common core: the assignments which we mutually explore and discuss and the SoTL (questioning and seeking evidence to answer those questions) process we employ and nurture in students. But we cannot have rigid expectations for the course or for any

As we interrelate our lives with each other, the course takes on different realities but still has a common core: the assignments which we mutually explore and discuss and the SoTL (questioning and seeking evidence to answer those questions) process we employ and nurture in students.

particular student outcomes in the course. We need to be open to where the course leads, having faith that we will end up in a place which educates students on the political and psychological realities of hate in the United States.

Ten years on, we have not been disappointed about the rich realities which we bring to and that result from the course. We both are active in the lives of our communities and thus bring multiple illustrations which are then used to explore the dynamism of negative political and psychological human behaviors. We also believe that we can progress to a better world because we can explore these issues in the relative safety of a college course. But we must always be aware that our examples are live examples which student can respond to and find in their own lives. The world becomes a living classroom. The classroom becomes a laboratory to discuss and revise these lived experiences. So, outside of some general conditions, truth is constructed and reality developed in such ways as to educate students to be creative consumers in their communities. Their ability to be creative learners is essential in a democracy where civic engagement often loses ground to artfully created but absolutist scenarios of human relationships.

InSight: A Journal of Scholarly Teaching 


\section{Faculty Change with Time}

How do we convince students that the world is neither too fragile nor too rigid for them to change? How do we convince students that to be involved in the community is not only essential for the health of a democratic society but actually a fun and useful exercise? How do we convince anyone that the fresh air of exploration and discovery is bracing to the spirit? How do we motivate the discussion, exploration and, yes, failure which lead to retooled successes? The best way that we know is to model these behaviors ourselves! We must indicate that not knowing is a plus and not a negative but that ignorance is to be explored. We must illustrate that observation and analysis of our situation, combined with a healthy respect for our own ability to succeed, will allow us to move ahead. We need to repeat over again that our major obstacle is our own fear of newness, our own belief in our own inability to land on our feet; even if we land in ways that are not always where we wish to be. We need to be our own best friend as well as our own worst enemy. We as faculty need to be the change agents we tell our students that they need to be. It is our experience that the dynamic "growth" process advocated by a SoTL paradigm (i.e., posing a question about one's knowledge or about another's learning and examining that knowledge or learning through evidence) allows for such change. By focusing more on the process of teaching and learning and less on

By focusing more on the process of teaching and learning and less on rigid content, we can create learning environments where positive change is illustrated over and over again as the way to live one's life.

rigid content, we can create learning environments where positive change is illustrated over and over again as the way to live one's life. We need to create exercises within these classes that repeatedly say that failure is a success not yet discovered as long as we learn from that failure. We need to nurture students' ability to "go where no one has ever gone before" with cheerfulness that denies doubt or failure.

The risk of this type of course is in not having the class entirely mapped out before we add students to the mix. We need to ask leading questions but refuse to provide leading responses. We need to challenge the norm when the norm is what students have been rewarded for espousing before. We will, at times, fall flat on our faces. We will, at times, be dead wrong. But, as we tell the students, being wrong is only a "problem" if we are searching for the correct answer. Still, students cannot learn to be creative and to succeed if they do not have the tools for success. One of the most important of these tools is the knowledge that failure is often necessary before success. They need to build up inner resources to prevail over challenges. Developing many pathways to a conclusion is essential to this task. Courses based on process laden experiences allow students to take these steps.

\section{Incorporating SoTL into the Course}

When one says, "I believe in the use of the scholarship of teaching and learning in my courses," it is easy to value this concept; but how, exactly, does one accomplish that use? What is meant by the SoTL process? As we mentioned in the introduction, we discovered SoTL quite by accident. Our colleagues demanded to know how we intended to teach a value-based course with content that would shift with each new crop of students or each highly publicized example of hate at the state, local, national and/or international level. Hence we searched for a framework to put our desires into words; SoTL provided that framework. As we began to articulate these goals within a SoTL framework, we discovered a process for partnering with our students that has served as the foundation of our course for a decade. Before expecting students to "pose questions to themselves about their biases and values" - a critical component of the SoTL process, in our minds - we 
felt it necessary to lay ground rules for classroom behavior. Although we will briefly discuss the etiquette and SoTL process we developed here, we have included in the appendices to this paper tables that spell these out completely in case readers would find it useful to duplicate and use these.

Given the sensitive nature of the focus of the course - hatred - we felt obligated to outline a model of behavior for the classroom as students engaged in the questioning and evidence gathering process of SoTL. The fact that this course would be (and always has been) taught on the Internet made this even more necessary in our opinion. What follows is an abbreviated form of the course etiquette that we discuss in our syllabus:

1) respect for others (their viewpoints, their values, their beliefs);

2) the right to disagree but requires sensitivity to the viewpoints of others;

3) taking responsibility for being involved in developing the issues and topics relevant to this course;

4) active participation in all elements of the course;

5) continual feedback to the instructors about the course, course assignments, and individual viewpoints;

6) a commitment to the mutual exchange of ideas. This means we will not isolate definitive "answers" to the issues we raise, but we will actively explore and respect the multiple sides to those issues; and

7) a responsibility to "police" ourselves. We are attempting to develop a community and this requires trust. In order to develop trust, we must know that we can share our ideas and not be "attacked." This also requires that we allow other class members the same trust and freedom we expect.

But standards for behavior are not the primary focus in this course. They are a means to an end. The end we desire, of course, is an honest exploration of values that will result in a more inclusive worldview in the students. But values are emotional. By putting etiquette first, we believe we create an environment in which admitting that one is provincial, for example, is okay. What is not okay is to be so and not explore it. Thus, the SoTL process follows from the etiquette. Again, a fuller description of this process is presented in table form in the appendix for others to duplicate if desired. Briefly, the SoTL process we employ suggests that student work in addressing a course issue should require the exploration of evidence for the knowledge, opinions, and/or values that are being expressed. Specifically, we expect students to engage in four levels of analysis. These levels are:

1) Recitation - state known facts or opinions. A critical component of this step is to acknowledge what aspect(s) of what is being stated is factual and what is based on opinion.

2) Exploration - analyze the roots of those opinions or facts. This step requires digging below the surface of what is believed or known and working to discover the elements that have combined to result in that fact or that opinion.

3) Understanding - involves an awareness of other views and a comprehension of the difference(s) between one's own opinion (and the facts or other opinions upon which that opinion is based) and the opinions of others.

4) Appreciation - means a full awareness of the differences between our views and opinions and those of others. To truly appreciate differences, we must be aware of the nature of those differences. The active dialogue undertaken in the third step (understanding) should lead to an analysis of the opinion as recited by the other. The result should be a complete awareness of the similarities and differences between our own opinions (and the roots of those opinions) and those of the "other."

This model is used to assess student work. For example, students receive a feedback sheet about a posted assignment that includes a "score" for each level of 
the model. A copy of a sample feedback sheet is included in the Appendix. We perceive this model as a rubric that can be used to promote student engagement in the scholarship of learning and to complement our use of the model in the design of assignments and assessments to promote the scholarship of teaching.

\section{Teaching the Course on the Internet}

Perhaps one of the most surprising things about teaching this course on the Internet has been colleagues' perceptions about such an enterprise. Suffice it to say that many of our colleagues do not believe that such a course should be taught on the Internet. (By "such a course" we mean one that delves into sensitive topic issues and one that requires the personal exploration of one's values.) Our experience, however, has been quite the opposite. Recent work suggests Internetbased assignments can foster significant advancements in the critical questioning and evidence examining processes valued by those who employ SoTL (e.g., Osborne, Baughn \& Kriese, 2007). Because this piece is meant, however, to be primarily reflective, we provide a sample of student-posted comments to illustrate that a well-designed Internet course can, indeed, foster the development of the SoTL process.

"It is a very interesting hatred course due to the fact that it is online. I think that this gives people more freedom to speak about what is on their minds and how they feel about it. I don't have a problem expressing how I feel about a topic where I might in class be more reserved." KS

"...taking it online helps, because you can voice your opinion honestly without repercussions." JC

"...and because it is online there's an extreme comfort level. Not sitting in a classroom removes the fear of being openly ridiculed to your face for your opinions and thoughts and gives us a forum to openly discuss controversial topics that would otherwise be extremely uncomfortable." JG

\section{SoTL in a Cross-Disciplinary Course}

No one can see in all directions; no one has all of the best ways to proceed. Combining two strong positions makes each position stronger yet. A community of people provides a community of diverse alternations and perspectives which interweave to create a dynamic synergy. Team teaching allows exploring a similar set of issues from divergent views. Cross-disciplinary work, we believe, is prototypical to the SoTL approach. The teaching and the learning are never contained in the same place. The variety of approaches of two or more people, even if alike Cross-disciplinary work, we in preparation, delivers that material from their believe, is prototypical to own unique perspective. Teachers teach from a the SoTL approach. set of assumptions which can be augmented by someone who teaches that material from their own perspective. These perspectives develop directions which no single teacher could anticipate.

Cross-disciplinary work creates flexibility in perspectives not taken when one person alone is doing the work. Students are then encouraged to look at diverse ways of doing their own work when they see this diverse pedagogy being exampled by their instructors. Human behavior is made of conflicting experiences and habits of action and thought. No one approach to human action can provide an adequate approach to this behavior. Again, however, we believe the students can 
say it best. We end this section with another sampling of student comments that touch on the importance of the interdisciplinary nature of our course.

"It is nice to have a refreshingly optimistic approach to sharing and stating views. It is nice to be forced to view things from different disciplines and perspectives. I often get caught up with being ignored by those who hate and are discriminatory and forget that even one person open to the idea of inclusiveness may be listening and can, in turn, carry on my words and beliefs." WS

"I would tell them that they must indeed have an open mind to many different topics that are studied in this course. I would tell them that they will learn many new perspectives on many different subjects such as race, culture, politics, etc. I would tell them that their eyes would be opened to problems that we are facing that some of us don't even think about. Through this course and having to look at things from both psychological and political science perspectives, my eyes have been "re-opened" to some things that occur right here in the U.S. such as racism, prejudice, political choices, etc. I would tell them that if they weren't willing to be open-minded about this course, then they shouldn't take it because they would be mad and not learn anything." TN

"It is a very interesting hatred course due to the fact that it is online and taught by both a psychology and a political science professor. I think that this gives people more freedom to speak about what is on their minds and how they feel about it. The group work has been complicated to make sure we all get together but our discussions are always entertaining. I don't have a problem expressing how I feel about a topic where I might in class be more reserved." KS

\section{Summary}

We realize this piece is not, in and of itself, scholarly in nature. Ten years of teaching this course and implementing a process of scholarship of teaching and learning, however, has resulted in some "best practice" ideas and some "lessons learned" that we believe are beneficial for:

1) illustrating how to incorporate SoTL into a course,

2) how to assess the effectiveness of SoTL in a course,

3) how to share SoTL with students,

4) how to satisfy potentially critical colleagues about the usefulness of SoTL, and

5) how to develop a more inclusive worldview in students as a direct result of implementing a SoTL approach in the classroom.

It is our belief that a reflective piece, such as this, is of value for those who are new to SoTL and for providing potentially new ways of doing things to those who have been utilizing SoTL for some time. But, as we believe is always the case, the students can say it best. In closing then, we leave the reader with another sampling of student comments that we believe illustrate the additive value of incorporating a SoTL approach in the classroom.

"I am glad this course forces us to argue for the need for valueadded, civically engaged education, and to utilize critical thinking to prompt exploration of hidden assumptions and biases." AF 
"I agree with you, but I also feel some people need a place to start and need a forum like this to open up and explore the issues themselves and to be encouraged to think more critically before acting and instigating a movement without concrete ideas/opinions about a certain issue." WB

"I think what I have learned so far is that we have to agree to disagree. Not everyone is going to see things like you do. If that were the case we wouldn't have anything to talk about. I've also learned we have got to critically think about and evaluate what we are talking about. I've also learned to respect the fact that each of us have been raised with different values, beliefs and ideals of what is and isn't acceptable in society. Once we respect the fact that we are all different and don't see through the same set of eyes, then we can work on changing." IP

\section{References}

Hall, R., (2003). Forging a learning community? A pragmatic approach to forging a learning community. Arts and Humanities in Higher Education, 2, 155-172.

Hutchings, P. \& Shulman, L.S. (1999). The scholarship of teaching: New elaborations, new developments. Change, 31, 10-15.

Morrison, T. (2001). How can values be taught in the university? Michigan Quarterly Review, 40, 273-278.

Osborne, R.E., Baughn, N., \& Kriese, P. (2007). Bridging the gap between the humanities and the social sciences: A crisis resolved. The International Journal of the Humanities, 5, 61-65.
Streveler, R.A., Moskal, B.M \& Miller, R.L. (2003). Using Boyer's four forms of scholarship to advance engineering education. The Journal of Scholarship of Teaching and Learning, 3, 41-50.

Thomas, C. \& Butler, J. (2000). Diversity philosophy. Paper presented at the Race, Gender and Class conference, Southern University at New Orleans.

Wagner, M. (2005). Teaching humanities in new ways and teaching new humanities. The Humanist, 65, 11-14.

Walker, M. (2002). Pedagogy and the politics and purposes of higher education. Arts and Humanities in Higher Education, 1, 43-58.

Randall E. Osborne has conducted scholarship of teaching projects illustrating how to: (1) maximize learning in online courses, (2) minimize the challenges of teaching in an Internet format, (3) take advantage of the unique pedagogical features of online teaching, and (4) create online courses facilitating critical thinking and value exploration.

Paul Kriese' low socioeconomic upbringing near the waterfront of Buffalo, New York and his years as a professor of political science have taught him that "we cannot reconstruct an environment of tolerance and inclusiveness unless we are teaching people to deconstruct the causes of hate in the first place."

Heather Tobey is a senior at Texas State University who has taken a third of her classes online in order to obtain her Bachelors of Applied Science in Psychology. Without the use of the internet courses she would not have been able to pursue her educational goals as she is also a single mother of two and works fulltime. 
This is an Internet course. As such, the success of the course relies on active participation by each class member throughout the entire semester.

Even though we are the professors for the course, it is designed as a seminar course, meaning active participation from students is essential.

Although face-to-face interactions will not occur because of our use of the Internet, we do expect continual communication between members of the class and the course faculty. Even though this interaction will be over the Internet, we expect students to use the same etiquette that would be used in a classroom during faceto-face interactions. This etiquette includes:

1) respect for others (their viewpoints, their values, their beliefs);

2) the right to disagree but requires sensitivity to the viewpoints of others;

3) taking responsibility for being involved in developing the issues and topics relevant to this course;

4) active participation in all elements of the course;

5) continual feedback to the instructors about the course, course assignments, and individual viewpoints;

6) a commitment to the mutual exchange of ideas. This means we will not isolate definitive "answers" to the issues we raise but we will actively explore and respect the multiple sides to those issues; and

7) a responsibility to "police" ourselves. We are attempting to develop a community and this requires trust. In order to develop trust, we must know that we can share our ideas and not be "attacked." This also requires that we allow other class members the same trust and freedom we expect.

\section{Appendix B: A Model for the Scholarship of Teaching \& Learning}

We expect students to demonstrate a significant amount of critical thinking in this course. Because this is so important, we have developed and outlined below a model that you should use as you complete course assignments. Specifically, we believe that critical thinkers demonstrate the ability to address issues at each of the following levels:

1) Recitation - state known facts or opinions. A critical component of this step is to acknowledge what aspect(s) of what is being stated is factual and what is based on opinion.

2) Exploration - analyze the roots of those opinions or facts. This step requires digging below the surface of what is believed or known and working to discover the elements that have combined to result in that fact or that opinion. This is an initial analysis without an attempt to comprehend the impact of those facts or opinions.

3) Understanding - involves an awareness of other views and a comprehension of the difference(s) between one's own opinion (and the facts or other opinions upon which that opinion is based) and the opinions of others. To truly "understand" our own opinion in relationship to others, we must initiate an active dialogue with the other person about his or her opinions and the roots of those opinions. In other words, once we become aware of the roots of our own opinions, we must understand the roots of the opinions of others.

4) Appreciation - means a full awareness of the differences between our views and opinions and those of others. To truly appreciate differences, we must be aware of the nature of those differences. The active dialogue undertaken in the third step (understanding) should lead to an analysis of the opinion as recited by the other. The result should be a complete awareness of the similarities and differences between our own opinions 
(and the roots of those opinions) and those of the "other." Although we may still be aware that our opinions differ, we are now in a position to truly appreciate and value those differences.

In our view, it is important to acknowledge that "understanding" does not mean to "accept." The goal is not to get everyone to agree; the goal is to get people to truly explore and understand how and why opinions differ. To understand means to realize the circumstances and motivations that lead to difference and to realize that those differences are meaningful. It is our belief that discussing social issues (such as prejudice or racism) without requiring students to explore the roots of their views, to understand the roots of other views, and to appreciate the nature and importance of different views about those issues, perpetuates ignorance. To raise the issue without using the humanities model may simply reinforce prejudices by giving them voice without question.

\section{Appendix C: Assessment for Articulating Student Progress on Demonstrating Scholarly Learning}

Recitation - state known facts or opinions.

The posts from this student clearly state known facts or opinions

\begin{tabular}{|c|c|c|c|}
\hline $\begin{array}{l}\text { strongly } \\
\text { disagree }\end{array}$ & $\begin{array}{c}\text { somewhat } \\
\text { disagree }\end{array}$ & $\begin{array}{l}\text { neither } \\
\text { agree } \\
\text { nor disagree }\end{array}$ & $\begin{array}{c}\text { somewhat } \\
\text { agree }\end{array}$ \\
\hline
\end{tabular}

Exploration - analyze the roots of those opinions or facts.

The posts from this student effectively explore roots of opinions or facts

\begin{tabular}{|c|c|c|c|}
\hline $\begin{array}{l}\text { strongly } \\
\text { disagree }\end{array}$ & $\begin{array}{c}\text { somewhat } \\
\text { disagree }\end{array}$ & $\begin{array}{r}\text { neither } \\
\text { agree }\end{array}$ & $\begin{array}{c}\text { somewhat } \\
\text { agree }\end{array}$ \\
\hline
\end{tabular}

disagree disagree $\begin{gathered}\text { agree } \\ \text { nor disagree }\end{gathered}$

Understanding - involves an awareness of other views and a comprehension of the difference(s) between one's own opinion (and the facts or other opinions upon which that opinion is based) and the opinions of others.

The posts from this student reflect an understanding of the roots of the opinions of others.

\begin{tabular}{|c|c|c|c|}
\hline $\begin{array}{l}\text { strongly } \\
\text { disagree }\end{array}$ & $\begin{array}{c}\text { somewhat } \\
\text { disagree }\end{array}$ & $\begin{array}{l}\text { neither } \\
\text { agree } \\
\text { nor disagree }\end{array}$ & $\begin{array}{c}\text { somewhat } \\
\text { agree }\end{array}$ \\
\hline
\end{tabular}

Appreciation - means a full awareness of the differences between our views and opinions and those of others.

The posts from this student reflect an appreciation for the diverse opinions of others.

\begin{tabular}{|c|c|c|c|}
\hline $\begin{array}{l}\text { strongly } \\
\text { disagree }\end{array}$ & $\begin{array}{c}\text { somewhat } \\
\text { disagree }\end{array}$ & $\begin{array}{l}\text { neither } \\
\text { agree } \\
\text { nor disagree }\end{array}$ & $\begin{array}{c}\text { somewhat } \\
\text { agree }\end{array}$ \\
\hline
\end{tabular}

